\title{
ERRATUM
}

\section{The Simpson grade: abandon the scale but preserve the message}

TO THE READERSHIP: An error appeared in the article by Schwartz et al. (Schwartz TH, McDermott MW. The Simpson grade: abandon the scale but preserve the message. J Neurosurg. Published online October 9, 2020. doi:10.3171/2020.6.JNS201904).

In the section "Confusing the Simpson Grade With Maximal Safe Resection," the sentence below incorrectly stated "recurrence-free survival." The correct term is "recurrence rates."

Moreover, grade 0 resection was not attempted, and the 5- and 10-year recurrence rates were only $2.3 \%$ and $4.3 \%$, respectively.

The article has been corrected online as of March 5, 2021.

Theodore H. Schwartz, MD

Weill Cornell Medicine, NewYork-Presbyterian Hospital, New York, NY

Michael W. McDermott, MD

Herbert Wertheim College of Medicine, Florida International University,

Miami, FL

CORRESPONDING ARTICLE See pp 488-495.

INCLUDE WHEN CITING

Published online March 5, 2021; DOI: 10.3171/2021.2.JNS201904a.

CAANS 2021, except where prohibited by US copyright law 